\title{
Effect of Shear Flow on Crystallization of Sydiotactic Polypropylene/Clay Composites
}

\author{
Naveed Ahmad \\ Department of Chemical and \\ Material Engineering \\ College of Engineering \\ Northern Border University \\ Arar, Kingdom of Saudi Arabia
}

\author{
Elsayed Fouad \\ Department of Chemical and \\ Material Engineering \\ College of Engineering \\ Northern Border University \\ Arar, Kingdom of Saudi Arabia
}

\author{
Farooq Ahmad \\ Department of Chemical and \\ Material Engineering \\ College of Engineering, \\ Northern Border University \\ Arar, Kingdom of Saudi Arabia
}

\begin{abstract}
The high sensitivity of crystallization to shear flow is a subject of great research interest the last several years. A set of syndiotactic polypropylene/clay composite samples were used to examine the effect of shear flow on crystallization kinetics. This phenomenon alters both processing and material final properties. In the present work, the effects of clay contents and shear flow on the rate of flow induced crystallization were investigated using rheological technique. Small amplitude oscillatory shear experiments were performed using advanced rheometric expansion system (ARES). The crystallization rate is found to alter by both shear and clay contents in the polymer composites.
\end{abstract}

Keywords-shear flow; flow induced crystallization; syndiotactic polypropylene/clay composites; induction time; Deborah number; crystallization kinetics

\section{INTRODUCTION}

The enhancement in the rate of polymer crystallization due to the application of flow is known as flow induced crystallization. In other words flow induced crystallization can be defined as the process in which the rate of polymer crystallization is accelerated by the action of flow [1]. This phenomenon alters both processing and material final properties. The physics behind flow induced crystallization is simple. When a polymer is subjected to a flow, the polymer chains are oriented and stretched. This results to a decrease in the entropy or equivalent increase in free energy [2, 3]. This increase in free energy acts as a driving force and thus accelerates the polymer crystallization process by accelerating the rate of nucleation. In general, the process of crystallization occurs in two steps. In the 1st step, the formation of nuclei (stable nuclei) occurs, while in the 2 nd step the subsequent growth of crystallite occurs. The flow has an effect on the first step of crystallization (nucleation stage) [1]. The flow mechanism induced crystallization has been explained very well in $[2,3]$. The process can be explained as the stretching of long chains to form fibrous crystals. During the stretching process, distortion of chains from their most probable conformation results and hence a decrease in the conformational entropy occurs. If this deformation is maintained in this lower conformational entropy state, then less conformational entropy needs to be sacrificed by transforming to a crystalline state. The decrease in total entropy allows the crystallization to occur at high temperatures that will take place under quiescent conditions. Normally, the formation of such fibrous morphology is accompanied by the formation of an epitaxial layer over and around the inner fiber giving rise to the so called shish-kebab kind of morphology [3].

A critical review shows that the outside, kebab like regions are essentially folded chain regions comprised of chains which do not crystallize during the orientation process [2-5]. While, in the inner shish region, the formation of folded chain discs occurs due to nucleation events taking place on the surface of extended chains. In the light of the above discussion, the enhancement in the rate of crystallization process by the shear flow is due to the enhancement in the rate of nucleation. Numerous works regard nucleation kinetics [5]. According to [7], isothermal nucleation kinetics is expressed as:

$$
N=C k T \Delta G \exp \left(\frac{E a}{k T}\right) \exp \left[-\frac{K}{T(\Delta G) n}\right]
$$

where $N=$ Rate of nucleation, $k=$ Boltzmann's constant, $T=$ absolute temperature, $\Delta G=\mathrm{G}_{\mathrm{L}}-\mathrm{G}_{\mathrm{S}}=$ Volumetric free energy difference between liquid and crystalline phase and $K=$ constant containing geometrical and energetic factors of nucleus.

It is generally accepted that the shear flow contributes to the free energy difference appearing in (2).

$$
\Delta G=\Delta G f+\Delta G q
$$

where $\Delta G q$ and $\Delta G f$ refer to the free energy contribution under quiescent and shear flow conditions respectively. In order to investigate the influence of flow on crystallization, a characteristic time for the crystallization is measured. This is usually called induction time. It is the time required for the steady state of nucleation to be reached. Both induction time and nucleation rate are nearly inversely proportional. Induction times can also be measured by detecting the sharp upturn in the viscosity vs time curve under constant shear rate [9]. The ratio between the induction time under quiescent and flow conditions can be defined as: 


$$
\vartheta=N q / N f=1 / 1+\Delta G f / \Delta G q \exp \left[\frac{K}{T(\Delta G q) n}\right]
$$

where $q$ and $f$ refer to quiescent and flow conditions respectively. The dimensionless induction time is 1 under quiescent conditions, while it is less than 1 when the shear flow is applied .For steady shear flow

$$
\Delta G f=3 \operatorname{ckT\Gamma }(D e)
$$

where $D e$ is Deborah number. It is the product of the shear rate and the polymer reptation time. $\Gamma$ is dimensionless free energy, which is a function of $D e$. In order to evaluate $\vartheta$ for a given polymer under isothermal flow conditions several material properties are needed. The quiescent free energy requires the knowledge of the thermodynamic melting temperature $\left(T_{m}\right)$ and latent heat of fusion $\left(H_{o}\right)$.

$$
\Delta G q=H o\left(1-\frac{T}{T m}\right)
$$

Values of the quiescent crystallization constant $(K)$ and exponent $(n)$ are required for calculating $\vartheta$. Besides this some values of rheological parameters of polymer melts like repetition time $\left(T_{d}\right)$, entanglement density $\left(\rho_{\mathrm{e}}\right)$ and molecular weight between entanglements $\left(M_{e}\right)$ are also required. In case of polymer melting, the ability of the shear flow to produce conformation and morphological changes with respect to equilibrium and isotropic state results from the coupling between the shear flow intensity and relaxation behavior of the chain. According to the theory of repetition [6], chain segment conformation or orientation occurs only when the characteristic flow time $(\gamma-1)$ is smaller than the repetition or disengagement time $\mathrm{T}_{\mathrm{d}}$. In the other words chain stretching is possible only when $\gamma-1<T_{R}<T_{d}$. $T_{R}$, and $T_{d}$ are the rouse and disengagement times respectively. The effect of flow on the chain orientation and consequently on the flow induced crystallization has been explained in terms of a dimensional form by defining a Deborah number for the system as:

$$
D_{e}=\gamma T_{d}
$$

The above discussion clearly mimics that for $D e<1$, there will be no effect on the crystallization kinetics, whereas faster crystallization kinetics should be observed only in case of $D e>1$. Molecular structure factors like molecular weight, molecular weight distribution or polydispersity and tactility are the important structural properties in quantitatively determining the flow induced crystallization rate [8-10]. In case of monodisperse polymers, longer polymer chains will be more oriented than the shorter ones under the same flow conditions, as high molecular weight chain has longer relaxation times. The same applies on the polydisperse polymers. The presence of a long tail of molecular weight chains should enhance the flow induced nucleation rate. Fiber pulling experiments on the long series of isotactic polypropylenes of different molecular weight were conducted [10]. It was found that the overall crystallization kinetics exponentially increased upon increasing polymer's molecular weight at constant fixed shear rate $[10$, 11].

Authors in [11] conducted rheological flow induced crystallization experiments on the isotactic polypropylene samples of different molecular weight and molecular weight distribution. They found an increase in the rate of crystallization by increasing the molecular weight of the samples at constant shear rate. Furthermore, they found that after a combined thermo mechanical treatment which mainly caused a degradation of the high molecular weight tail, the effect of the shear rate on the crystallization rate was strongly reduced.

In [14], authors obtained the same results by investigating the process using differential scanning calorimetry (DSC) technique. They performed experiments on both linear and branched chain polypropylene. Long chain branched polypropylene showed accelerated crystallization kinetics in comparison with that of low branched level. The crystallization of long chain branched polypropylene was found more sensitive to shear flow than that of linear polypropylene during the induced period at low shear rates, which depicts that the longer relaxation time of the polymer chains played an important role in the nucleation of polypropylene under shear flow fields. In a nut shell an increase in molecular weight will produce a faster crystallization under given flow conditions.

Authors in [12] studied melt blended nanocomposites of $\mathrm{PP} /$ Talc. Nanocomposites of PP/Talc were processed using an internal mixer. An elongational rheometer was used to generate well controlled different extensional flow conditions. Samples were then characterized by WAXS to reveal and quantify the fillers and polypropylene crystalline phase orientation. Crystalline orientation of polypropylene was found to be strongly affected by the addition of Talc under extensional flow and Talc orientation. More recently, isotactic polypropylene (iPP) based single-polymer composites (SPCs) were prepared by introducing iPP fibers into the molten or super cooled homogeneous iPP matrix [13]. The influences of fiber introduction temperature $(\mathrm{Ti})$ on the resultant morphology of transcrystallinity $\left(T_{C}\right)$ and mechanical properties of SPCs were investigated via a polarized optical microscopy (POM) and a universal tensile test machine. The effects of interfacial crystallization on mechanical properties were also studied. The tensile strength of SPCs was observed to increase firstly and to reach a maximum value at $T_{i}=160^{\circ} \mathrm{C}$, and then to decrease with further increasing of $\mathrm{Ti}$. Wide-angle X-ray diffraction (WAXD), scanning electron microscopy (SEM) and POM were employed to understand the mechanical enhancement mechanism. It is found that the enhanced tensile strength of SPCs was strongly dependent on the synergistic effects of TC, high orientation degree of iPP fibers and good adhesion between the iPP fiber and the matrix. In the present work we studied the effect of clay loading and shear flow on the rate of crystallization of $\mathrm{sPP} /$ clay composites using rheological technique.

\section{EXPERIMENTAL WORK}

\section{A. Materials}

Samples of sPP/clay composites with different contents of clay were used for the flow induced crystallization study. The diagnostic properties of the polymers are reported in Table I. All the samples were synthesized in our chemistry department using solution mixing technique [15]. 
TABLE I. LIST OF ALL SAMPLES [15].

\begin{tabular}{|c|c|c|c|}
\hline $\begin{array}{c}\text { Sample } \\
\text { Number }\end{array}$ & $\begin{array}{c}\text { Sample } \\
\text { Name }\end{array}$ & $\begin{array}{c}\text { Percentage } \\
\text { of clay contents }\end{array}$ & $\begin{array}{c}\text { Degree of } \\
\text { syndiotacticity }<\% \text { rrr }>\end{array}$ \\
\hline 1 & sPP-1 & $10 \%$ & \\
\hline 2 & sPP-2 & $7.5 \%$ & \\
\hline 3 & sPP-3 & $5 \%$ & 60 \\
\hline 4 & sPP & 0 & \\
\hline
\end{tabular}

\section{B. Methodology}

The effects of shear flow and clay contents on the rate of crystallization (flow induced crystallization) were investigated by rheological technique using ARES rheometer. Before staring the flow induced crystallization experiments stability and range of shear stress were explored for each sample. After confirming the stability and determining the range of shear stress, the effect of shear flow on crystallization was examined at two different temperatures above and below the melting point. In case of sPP-1, shear flow was applied at $145^{\circ} \mathrm{C}$ and $125^{\circ} \mathrm{C}$, while in case of sPP-3, the shear flow was applied at $120^{\circ} \mathrm{C}$ and $105^{\circ} \mathrm{C}$. The procedure of the rheological flow induced crystallization experiments is explained below:

1. Annealing of the polymer sample was carried out by time sweep test at $220^{\circ} \mathrm{C}$ for 20 minutes in order to clean the sample.

2. The polymer sample was cooled from $220^{\circ} \mathrm{C}$ to temperatures above melting temperature by temperature ramp test at a constant cooling rate of $40^{\circ} \mathrm{C} / \mathrm{min}, 1 \mathrm{rad} / \mathrm{s}$ of frequency and at a strain of $1 \%$.

3. Different shear rates ranging from 0.01 to $0.25 \mathrm{~s}^{-1}$ were applied at a specific temperature.

4. After the application of shear rate, temperature ramp test (crystallization test) was started within a time of 13 seconds.

5. In another set of experiments shear rate was applied at a temperature below melting point. Different shear rates within the range $\left(0.01\right.$ to $\left.0.25 \mathrm{~s}^{-1}\right)$ were applied at $125^{\circ} \mathrm{C}$ and $105^{\circ} \mathrm{C}$ respectively for $\mathrm{sPP}-1$ and $\mathrm{sPP}-3$ respectively within the induction time for different periods of time (shear flow times). Both sets of experiments were carried out for all samples.

\section{RESULTS AND DISCUSSION}

Annealing of the samples by time sweep test at $220^{\circ} \mathrm{C}$ and $1 \mathrm{rad} / \mathrm{s}$ was carried out for 20 minutes in order to investigate the stability and clean the sample completely from the spherulites and nuclei. Time sweep test for sPP-1 has been shown in Figure 1. Thermal stability of all samples was examined at $220^{\circ} \mathrm{C}$ and at $1 \mathrm{rad} / \mathrm{s}$ of frequency. All the samples were found to be stable. After confirming the thermal stability, the stability of the samples was examined for different shear rates. All the samples were found stable in the range of 0.01 to $0.25 \mathrm{~s}^{-1}$ of shear rates as shown in Figure 2 for sPP-1. Crystallization behavior under quiescent conditions and at different shear rates was explored using the temperature ramp test from 220 to $125^{\circ} \mathrm{C}$ for sPP-1. Different shear rates were applied at $125^{\circ} \mathrm{C}$ after cooling from $220^{\circ} \mathrm{C}$. In case of quiescent condition, no shear rate was applied at $125^{\circ} \mathrm{C}$. In both cases of quiescent and flow induced crystallization, crystallization behavior was observed by cooling from $220^{\circ} \mathrm{C}$ to $125^{\circ} \mathrm{C}$. Changes in moduli dictate the process of crystallization. Jump in the elastic modulus after the incubation and induction time is considered as the actual crystallization process. Enhancement in the rate of crystallization was observed by the application of different shear rates. In another words the induction time is not the same in all cases. These findings have been exhibited graphically in Figure 3.

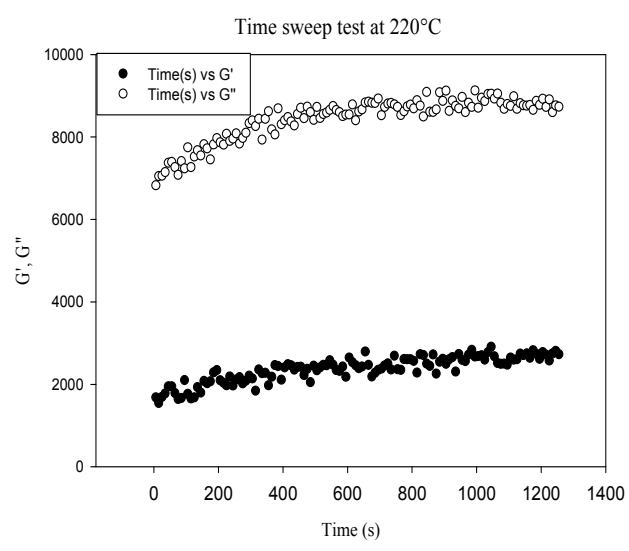

Fig. 1. Time sweep test for sPP- 1 at $220^{\circ} \mathrm{C}$.

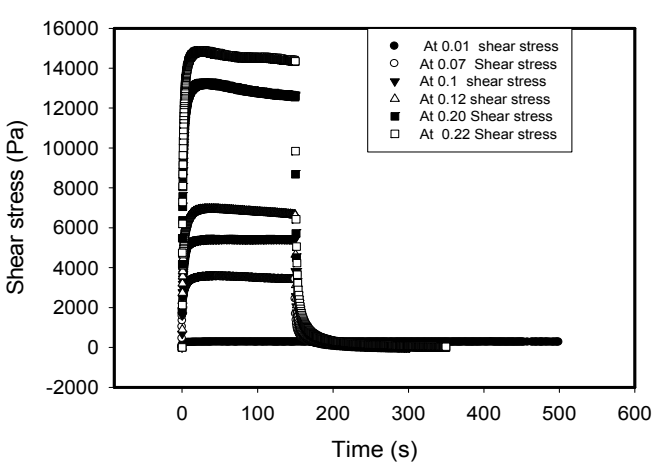

Fig. 2. Plot between time and shear stress for sPP-1.

In order to investigate the effect of shear flow on crystallization process, some other types of experiments were conducted on SPP-11 and sPP-5. In these experiments, different shear flows were applied within the induction time at temperatures below and above melting point after cooling from $200^{\circ} \mathrm{C}$ for all samples. Each shear flow was applied for different periods of time ranging from 50 to 800 seconds depending upon on the induction time of the sample.

A significant effect of shear flows was found on the crystallization kinetics. The characteristic Deborah number was calculated from the relaxation time and shear flows. Relaxation time was calculated by different methods. In all cases the Deborah number was found greater than one $(D e>1)$, which verifies our experimental findings that the applied shear flow is able to orient the polymer chains. Shear flow can be increased to the extent of making Deborah number greater. In the present experimental work this attempt was made, but the sample was 
found to come out from the rheometer plates, which confirmed that in the present experimental set up higher shear flows cannot be applied. Deborah number was found to increase with increase in the shear rate. In all cases it was found greater than one. The same trend was found in case of shear flow times. Deborah number was found to increase with increase in the shear flow time. The relationship between shear flows and Deborah number is shown in Figure 5. It was found that induction time decreases with increasing of the clay contents. Increase in clay contents increases the time of crystals formation. The relationship between clay contents and induction is shown in Figure 6.

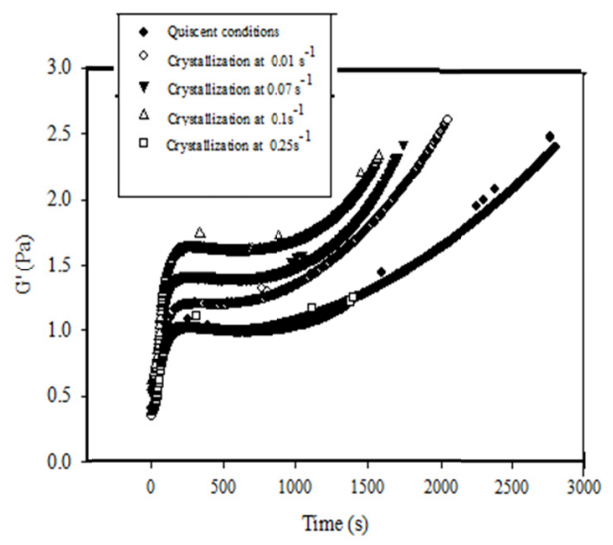

Fig. 3. Crystallization under quiescent conditions and at different shear rates for $\mathrm{SPP}-1$.

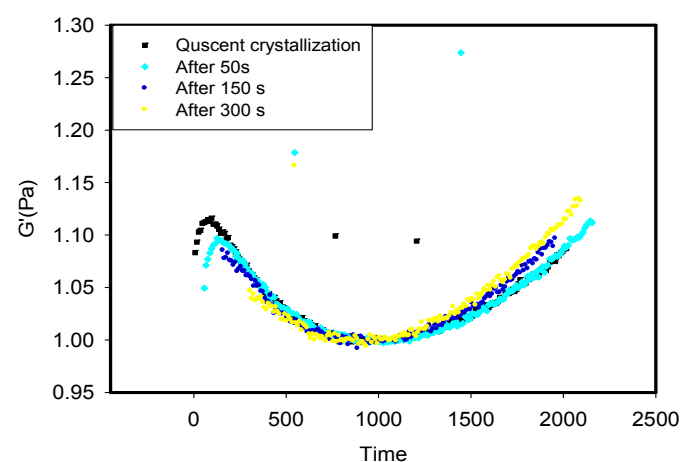

Fig. 4. Crystallization of sPP-2 at a shear rate of $0.07 \mathrm{~s}^{-1}$ for different periods of time at $80^{\circ} \mathrm{C}$.

\section{CONCLUSION}

Crystallization measurements performed on sPP/clay composites at different shear rates show that there is influence of shear flow in the range of 0.01 to $0.25 \mathrm{~s}^{-1}$ on crystallization behavior. The Deborah number calculated for all the samples at different shear rates was found greater than one, which verified our findings of effect of shear flow on the crystallization behavior of sPP/clay composites in the given range of shear rates. The effect of clay contents on crystallization kinetics was found. Increase in clay contents increases the crystallization kinetics. The rate of crystallization was found to increase with increase in clay contents. That's why induction time decreases with increase in the clay contents.

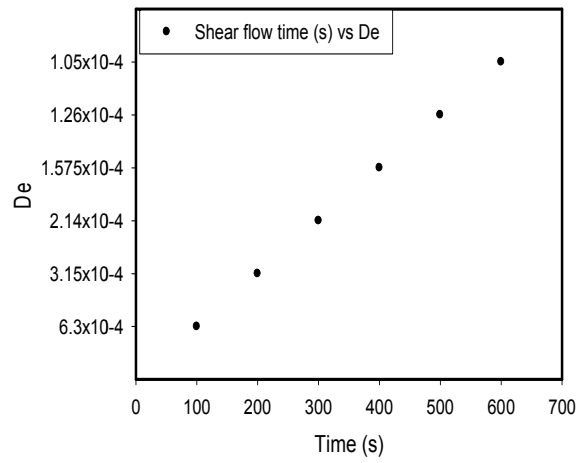

Fig. 5. Relationship between shear flow time and Deborah number.

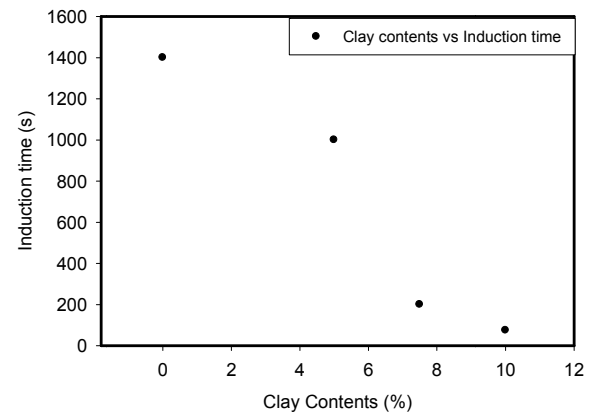

Fig. 6. Relationship between clay and contents and induction time.

\section{ACKNOWLEDGEMENT}

Authors wish to acknowledge the support of this research study by the grant No.6857-ENG-2016-1-6-F from the Deanship of Scientific Research in Northern Border University, Arar, Kingdom of Saudi Arabia.

\section{REFERENCES}

[1] H. Janeschitz-Kriegl, E. Ratajski, M. Stadlbauer, "Flow as an effective promotor of nucleation in polymer melts: A quantitative evaluation", Rheological Acta, Vol. 42, No. 4, pp. 355-364, 2003

[2] R. H. Somani, L. Yang, B. S. Hsiao, T. Sun, N. V. Pogodina, A. Lustiger, "Shear-induced molecular orientation and crystallization in isotactic polypropylene: Effects of the deformation rate and strain", Macromolecules, Vol. 38, No. 4, pp. 1244-1255, 2005

[3] R. H. Somani, L. Yang, L. Zhu, B. S. Hsiao, "Flow-induced shish-kebab precursor structures in entangled polymer melts", Polymer, Vol. 46, No. 20, pp. 8587-8623, 2005

[4] E. W. Fischer, M. Stamm, M. Dettenmair, "Organization of the Macromolecules in the condensed Phase", in: Faraday Discussions of the Royal Society of Chemistry, Vol. 68, 1980

[5] J. Stejny, J. Dlugosz, A. Keller, "Electron microscope diffraction characterization of the fibrous structure of poly (sulphur nitride) crystals", Journal of Materials Science, Vol. 14, No. 6, pp. 1291-1300, 1979

[6] S. T. Milner, T. C. B. Mc Leish, "Reptation and contour-length fluctuations in melts of linear polymers", Physical Review Letters, Vol. 81 , No. 3, pp. 725-728, 1998 
[7] J. I. Lauritzen Jr, J. D. Hoffman, "Formation of polymer crystals with folded chains from dilute solution", The Journal of Chemical Physics, Vol. 31, No. 6, pp. 1680-1681, 1959

[8] S. Acierno, N. Grizzuti, H. H. Winter, "Effects of Molecular Weight on the Isothermal Crystallization of Poly(1-butene)", Macromolecules, Vol 35 , No. 13 , pp. 5043-5048, 2002

[9] S. Acierno, N. Grizzuti, "Flow-induced crystallization of polymer: theory and experiments", International Journal of Material Forming, Vol. 1, pp. 583-586, 2008

[10] C. Duplay, B. Monasse, J. M. Haudin, J. L. Costa, "Shear-induced crystallization of polypropylene: Influence of molecular weight", Journal of Materials Science, Vol. 35, No. 24, pp. 6093-6103, 2000

[11] S. Vleeshouwers, H. E. H. Meijer, "A rheological study of shear induced crystallization", Rheological Acta, Vol. 35, No. 5, pp. 391-399, 1996

[12] M. Khalil, P. Hebraud, A. Mcheik, H. Mortada, H. Lakiss, T. Hamieh, "Elongational flow-induced crystallization in polypropylene/talc nanocomposites", Physics Procedia, Vol. 55, pp. 259-264, 2014

[13] L. Zhang, Y. Qin, G. Zheng, K. Dai, C. Liu, X. Yan, J. Guo, C. Shen, Z. Guo, "Interfacial crystallization and mechanical property of isotactic polypropylene based single-polymer composites", Polymer (UK), Vol. 90, pp. $18-25,2016$

[14] F. Hernandez Sanchez, L. F. del Castillo, R. Vera-Graziano, "Isothermal crystallization kinetics of polypropylene by differential scanning calorimetry, I. Experimental conditions", Journal of Applied Polymer Science, Vol. 92, pp. 970-978, 2004 